\title{
Maternal and Neonatal Outcome for Singleton and Twin Pregnancies in Emergency Cesarean Section vs. Urgent Cesarean Section in a Retrospective Evaluation from 2003-2012
}

\author{
Andrea Mölgg, Stefan Jirecek, Victoria Girtler, Rainer Lehner* \\ Department of Obstetrics and Gynecology, Medical University of Vienna, Vienna, Austria \\ Email: ${ }^{*}$ rainer.lehner@meduniwien.ac.at
}

Received 29 August 2014; revised 23 September 2014; accepted 15 October 2014

Academic Editor: Moon Whanim, Inha University School of Medicine, South Korea

Copyright (C) 2014 by authors and Scientific Research Publishing Inc.

This work is licensed under the Creative Commons Attribution International License (CC BY). http://creativecommons.org/licenses/by/4.0/

(c) (7) Open Access

\begin{abstract}
Objectives: Emergency cesarean is performed, when a situation requires immediate action in order to reduce the risk to mother and/or child, while urgent cesarean is done if a non-life threatening but compromising situation occurs. The aim of the study was to investigate the maternal and fetal outcome for emergency and urgent cesarean. Study Design: A retrospective case-control study was performed; cases underwent emergency cesarean section, while controls underwent urgent cesarean section. We included 303 cases of women and 336 cases of children, and controls were matched. Maternal and fetal outcome parameters for singleton and twin pregnancies were investigated using the Wilcoxon test and the Chi-square-test. Results: Maternal outcome: Higher blood loss (cases: mean $383.12 \pm 232.89$, range 100 - 2500 vs. controls: $336.06 \pm 129.19$, range 100 $1000, p=0.008)$, hemorrhage ( 34 vs. 11, $p<0.001$ ) and puerperal anemia (30 vs. 10, $p<0.001)$. Neonatal outcome: One, five, and ten minutes Apgar levels and umbilical cord $\mathrm{pH}$ values are lower for cases $(p<0.001$ and $p<0.001$, respectively). Twins had lower five and ten minutes Apgar levels $(p=0.040$ and 0.002$)$, but higher umbilical cord $p H$ values than singletons $(p<0.001)$. The perinatal mortality among singletons was $3.8 \%$, among twins $\mathbf{8 . 1 \%}$. For cases the perinatal mortality among singletons was $5.7 \%$ and $17.14 \%$ for twins (control group $1.41 \%$ and $2.63 \%$, respectively). Conclusion: The maternal and fetal outcome is poorer in emergency cesarean section. Especially the perinatal mortality is high in emergency cesarean section, particular for twins.
\end{abstract}

\footnotetext{
*Corresponding author.
} 


\section{Keywords}

\section{Emergency Cesarean Section, Maternal Outcome, Neonatal Outcome, Twins, Urgent Cesarean Section}

\section{Introduction}

Previous published data classified cesarean, which were not performed as an elective cesarean, in an inconsistent way. The cases, classified as emergency cesareans, were very inhomogeneous. Lucas et al. performed a study in the year 2000 which had the aim to set a new classification for emergency cesareans, and they proposed the following:

1) Emergency cesarean: immediate threat of life for woman or fetus;

2) Urgent: maternal or fetal compromise which is not immediately life threatening;

3) Scheduled: needing early delivery but no maternal or fetal compromise;

4) Elective: at a time to suit the woman and the maternity team [1].

Emergency cesarean section (ECS) is conducted, when a situation requires immediate action for decreasing the risk to mother and/or child, e.g. placental abruption, bleeding caused by placenta previa or imminent intrauterine asphyxia [2] [3]. An urgent cesarean section (UCS) was conducted during birth process, though a vaginal birth was planned, e.g. a protracted birth [3]. The performance and specifically the time management of emergency cesarean section were discussed in many studies, especially regarding the decision-to-delivery interval (DDI).

The DDI is the time interval between the decision to perform a cesarean and the delivery of the child [4] [5]. The German society for gynecology and obstetrics allows a DDI of 20 minutes, while the American College of Obstetricians and Gynecologists and the Royal College of Obstetricians and Gynecologists recommend a DDI of 30 minutes [6] [7].

To obey the recommendation of 20 minutes in our institution, a tertiary care hospital with 3500 births per year, the management of emergency cesareans was adapted to the following:

1) On admission the patients are screened for risk factors which could predict complications, e.g. twin pregnancies, former cesareans, especially former emergency of urgent cesarean sections or intrauterine fetal retardation. If risk factors are found, the patients are admitted in a special equipped delivery room (with equipment as lamps or anesthesia machine for an emergency cesarean).

2) If these patients would need an emergency cesarean, it is directly performed in the delivery room.

3) After consultation with the anesthesiologist women without former epidural anesthesia received general anesthesia.

4) The obstetric staff is equipped with an ECS beeper. When ECS alarm is given, the staff has to call back immediately. In the ECS protocol the time of the alarm, the call back time, the indication for the ECS, the gestational age, the birth weight, the $\mathrm{pH}$ and the Apgar score are registered.

Due to consequent implementation of these steps and good interdisciplinary communication, the DDI decreased from average 15.39 to 9.43 minutes.

Although the recommended 20 minutes are an accurate goal in most patients, the situation itself has high stress potential for women and child, and the life threatening situation leading to the decision to undertake an ECS could also affect the outcome. Recommendations for time management for UCS do not exist.

The aim of the study was to investigate the maternal and neonatal outcomes for ECS and UCS, in respect.

\section{Methods}

The study was conducted as a case-control study. In the study period from 2003 to 2012 all women undergoing a cesarean section in our institution were recorded in an in-house database. All women undergoing an ECS in the study period (singleton and twin pregnancies) were included in the case group. Controls were matched by age.

All children (singleton and twins) born by ECS during the study period were included in the case group, controls were matched by sex and gestational age.

In the case group 303 women and 336 children were included and 303 women and 336 children were matched 
as controls.

The maternal outcome was defined by blood loss, hemorrhage, integrity of the placenta, anomaly of placental separation, eclampsia, hysterectomy, puerperal fever, sepsis, anemia and death. The new-born outcome was defined by stillbirth, Apgar score, umbilical cord $\mathrm{pH}$, admission to NICU and death within seven days.

The study was approved by the local ethic committee (\#1282/2013, 17.04.2013).

\section{Statistics}

First descriptive analyses were performed to describe both groups. Epidemiologic and anamnestic parameters were compared, e.g. age, obstetric parameters, gestational age, weight of the new-born, sex or malformations. The frequency of maternal and neonatal morbidities were investigated and compared between cases and controls, also regarding singleton and twin pregnancies. The Wilcoxon test and the Chi-square-test were conducted. $\mathrm{p}<$ 0.05 was considered statistically significant. All statistical analyses were performed with IBM SPSS Statistics 19 for windows.

\section{Results}

\subsection{Maternal Outcome}

The women age ranged from 15 to 51 (median 31, mean $30.73 \pm 6.63$ ). The obstetric parameters are listed in Table 1. No differences were was found between the two groups.

Table 1. Descriptive parameters cases vs. controls.

\begin{tabular}{|c|c|c|c|}
\hline & ECS & UCS & p-value \\
\hline Total women & 303 & 303 & \\
\hline Age & $31(30.82 \pm 6.58)$ & $31(30.65 \pm 6.79)$ & \\
\hline Gestation week & $36(34.56 \pm 6.02)$ & $38(36.56 \pm 4.47)$ & $<0.001$ Wilcoxon test \\
\hline Gravida & $2(2.43 \pm 2.78,1-38)$ & $2(2.42 \pm 1.73,1-12)$ & \\
\hline Para & $1(1.80 \pm 1.24,1-8)$ & $1(1.86 \pm 1.30,1-12)$ & \\
\hline Live birth & $1(1.28 \pm 1.35,0-7)$ & $1(1.32 \pm 1.36,0-10)$ & \\
\hline Stillbirth & $0(0.04 \pm 0.19,0-1)$ & $0(0.04 \pm 0.20,0-1)$ & \\
\hline Abortus & $0(0.54 \pm 0.84,0-5)$ & $0(0.66 \pm 1.00,0-6)$ & \\
\hline Abruptio & $0(0.49 \pm 2.60,0-32)$ & $0(0.19 \pm 0.56,0-4)$ & \\
\hline General anesthesia & 175 (of $303,57.75 \%$ ) & 8 (of $303,2.64 \%$ ) & $<0.001$ Chi square test \\
\hline Spinal anesthesia & 61 (of 303, 20.13\%) & 212 (of 303, 69.96\%) & $<0.001$ Chi square test \\
\hline Induction of labor & 29 (of $303,9.57 \%$ ) & 51 (of 303, 16.83\%) & 0.011 Chi square test \\
\hline Oxitocin for bradytocia & 28 (of $303,9.24 \%$ ) & 54 (of 303, 17.82\%) & 0.011 Chi square test \\
\hline Total neonates & 336 & 336 & \\
\hline Sex & 199 male, 137 female & 199 male, 137 female & \\
\hline Week of gestation & $35(34.10 \pm 5.97)$ & $35(34.23 \pm 5.472)$ & \\
\hline Head circumference & $33(31.63 \pm 4.00)$ & $33(31.53 \pm 4.02)$ & \\
\hline Weight (g) & $2280(2274.76 \pm 1050.54)$ & $2370(2348.41 \pm 1068.12)$ & \\
\hline Length (cm) & $49(46.17 \pm 6.59)$ & $48(45.72 \pm 7.184)$ & \\
\hline Malformations & 5 (of $336,1.48 \%$ ) & 7 (of 336, 2.08\%) & \\
\hline
\end{tabular}

ECS: emergency cesarean section, UCS: urgent cesarean section. 
The women had the same median BMI and weight, no differences were found regarding infections status as HIV, hepatitis, toxoplasmosis or lues.

Premature rupture of membranes was found in 80 cases and 100 controls, the difference was significant $(\mathrm{p}=$ 0.004). 29 cases and 51 controls had induction of labor $(p=0.011)$. Women undergoing ECS had general anesthesia more often than women undergoing UCS (175 cases vs. 8 controls), while controls were more likely to have a spinal anesthesia (61 cases vs. 212 controls; $\mathrm{p}<0.001$ ). Use of oxitocin for bradytocia was found in 28 cases and 53 controls $(p=0.011)$. The most common fetal presentation was vertex presentation $(n=405$, $66.83 \%)$, followed by breech presentation $(n=56,9.24 \%)$. The most common indications for ECS were imminent intrauterine asphyxia and unspecified threat of life of the fetus, for UCS the most common indication was protracted birth. The median week of gestation in the case group was $36^{\text {th }}$ (mean $34.56 \pm 6.02$ ), in the control group $38^{\text {th }}$ (mean $36.65 \pm 4.47$; $\mathrm{p}<0.001$ ).

The blood loss in the case group was higher than in the control group (cases: mean $383.12 \pm 232.89$, range 100 - 2500 vs. controls: $336.06 \pm 129.19$, range $100-1000$, $p=0.008)$. Hemorrhage was found in 34 cases and 11 controls ( $\mathrm{p}<0.001)$. 30 cases and 10 controls had anemia $(\mathrm{p}<0.001)$, the median hemoglobin level of patients with anemia was 8.9 for cases and 9.40 for controls (cases: mean $8.59 \pm 1.11$, range $6.6-9.9 \mathrm{~g} / \mathrm{dl}$ vs. controls: mean $9.01 \pm 0.90$, range $7.7-9.9 \mathrm{~g} / \mathrm{dl})$.

Regarding integrity of the placenta, anomaly of placental separation, eclampsia, hysterectomy, puerperal fever and sepsis no differences were found between the two groups. No maternal death was recorded.

We investigated, if there is a difference between singleton and twin pregnancies. 521 singleton and 85 twin pregnancies were found. No differences were found regarding blood loss, hemorrhage, integrity of the placenta, anomaly of placental separation, eclampsia, hysterectomy, puerperal fever, sepsis and anemia.

No differences were found between singleton and twin pregnancies in the case and control group.

\subsection{Neonatal Outcome}

The children were in the $35^{\text {th }}$ week of gestation (mean $24.17 \pm 5.72$ ). 398 were male, 274 female. No significant differences were found regarding head circumference, weight, height and frequency of malformations (see Table 1).

The Apgar levels at one, five and ten minutes were lower in the case group than in the control group ( $<<$ 0.001). The umbilical cord $\mathrm{pH}$ level was also lower in the case group $(\mathrm{p}<0.001)$. The data is shown in Table 2 and graphs 1 and 2. Children born by ECS were more likely to be transferred to the NICU than children born by UCS (169 vs. $135, \mathrm{p}=0.002)$. 7 stillbirths were found in the case group vs. 1 stillbirth in the control group. Of

Table 2. Apgar scores and umbilical cord $\mathrm{pH}$ values cases vs. controls with comparison of singletons and twins.

\begin{tabular}{|c|c|c|c|c|}
\hline \multicolumn{4}{|c|}{ Cases } & \multirow[b]{2}{*}{ p-value } \\
\hline & All $(n=336)$ & Singletons $(\mathrm{n}=266)$ & Twins $(\mathrm{n}=70)$ & \\
\hline APGAR 1 & $8(6.61 \pm 2.63)$ & & & \\
\hline APGAR 5 & $9(8.13 \pm 2.37)$ & & & \\
\hline APGAR 10 & $9(8.61 \pm 2.37)$ & $9(8.73 \pm 2.23)$ & $9(8.15 \pm 2.87)$ & 0.046 \\
\hline \multirow[t]{3}{*}{ Umbilical cord $\mathrm{pH}$ value } & $7.20(7.16 \pm 0.15)$ & $7.19(7.15 \pm 0.15)$ & $7.25(7.21 \pm 0.12)$ & 0.004 \\
\hline & Controls & & & \\
\hline & All $(n=336)$ & Singletons $(\mathrm{n}=222)$ & Twins $(\mathrm{n}=114)$ & p-value \\
\hline APGAR 1 & $8(8.06 \pm 1.48)$ & $9(8.11 \pm 1.58)$ & $8(8.00 \pm 1.33)$ & 0.004 \\
\hline APGAR 5 & $9(9.05 \pm 1.32)$ & $10(9.19 \pm 1.34)$ & $9(8.83 \pm 1.27)$ & $<0.001$ \\
\hline APGAR 10 & $10(9.05 \pm 1.24)$ & $10(9.46 \pm 1.32)$ & $9(9.28 \pm 1.09)$ & $<0.001$ \\
\hline Umbilical cord $\mathrm{pH}$ value & $7.29(7.27 \pm 0.08)$ & & & \\
\hline
\end{tabular}

Differences between cases and controls for APGAR 1, APGAR 5, APGAR 10, and umbilical cord pH were significant with $\mathrm{p}<0.001$. The data was evaluated with the Wilcoxon test. 
336 children in the case group 21 died within the first week, in the control group 5 children died within the first week $(\mathrm{p}<0.001)$. The most common reasons were respiratory problems and immaturity due to preterm delivery. The perinatal mortality was $8.3 \%$ for cases and $1.7 \%$ for controls.

471 children were singletons and 184 were twins. The Apgar levels after five and ten minutes and the umbilical cord $\mathrm{pH}$ were not the same among singletons and twins. The Apgar level after five minutes were higher for singletons than for twins (median 9, mean $8.65 \pm 1.97$ vs. median 9, mean $8.53 \pm 1.88, \mathrm{p}=0.040$ ). The Apgar level after 10 minutes were higher for singletons than for twins (median 10, mean $9.06 \pm 1.91$ vs. median 9 , mean $8.90 \pm 1.95, \mathrm{p}=0.002$ ). Twins had higher umbilical cord $\mathrm{pH}$ levels than singletons (median 7.28, mean $7.26 \pm 0.09$ vs. median 7.24, mean $7.20 \pm 1.91$, p < 0.001) (Figure 1, Figure 2).

The data for cases and controls are shown in Table 2.

183 (of 399, 45.86\%) of singletons were transferred to NICU, 107 (of 156, 68.58\%) of twins were transferred to NICU $(\mathrm{p}<0.001)$.

The perinatal mortality among singletons was 3.8\%, among twins $8.1 \%$. In the case group (ECS-259 singletons and 70 twins) the perinatal mortality among singletons was 5.7\% (2 stillbirths and 13 deaths within the first week) and $17.14 \%$ for twins (5 stillbirths and 7 deaths within the first week). In the control group (UCS-212 singletons and 114 twins) the perinatal mortality among singletons was $1.41 \%$ (0 stillbirths and 3 deaths within the first week) and 2.63\% for twins (1 stillbirth and 2 deaths within the first week).

$54.26 \%$ of Singletons born by ECS were transferred to NICU, twins $77.7 \%$. For UCS it was $35.22 \%$ and $63.72 \%$, respectively.

The outcome was investigated regarding the sequence at the birth. No differences were found for the Apgar levels, the umbilical cord $\mathrm{pH}$, transfer to NICU or perinatal mortality between the first or the second born twin.

\section{Discussion}

An unpredictable event, which leads to the conduction of an ECS, is a strong stressor for the mother and her child. The additional stress may influence the maternal and neonatal outcome. Differences in the maternal and

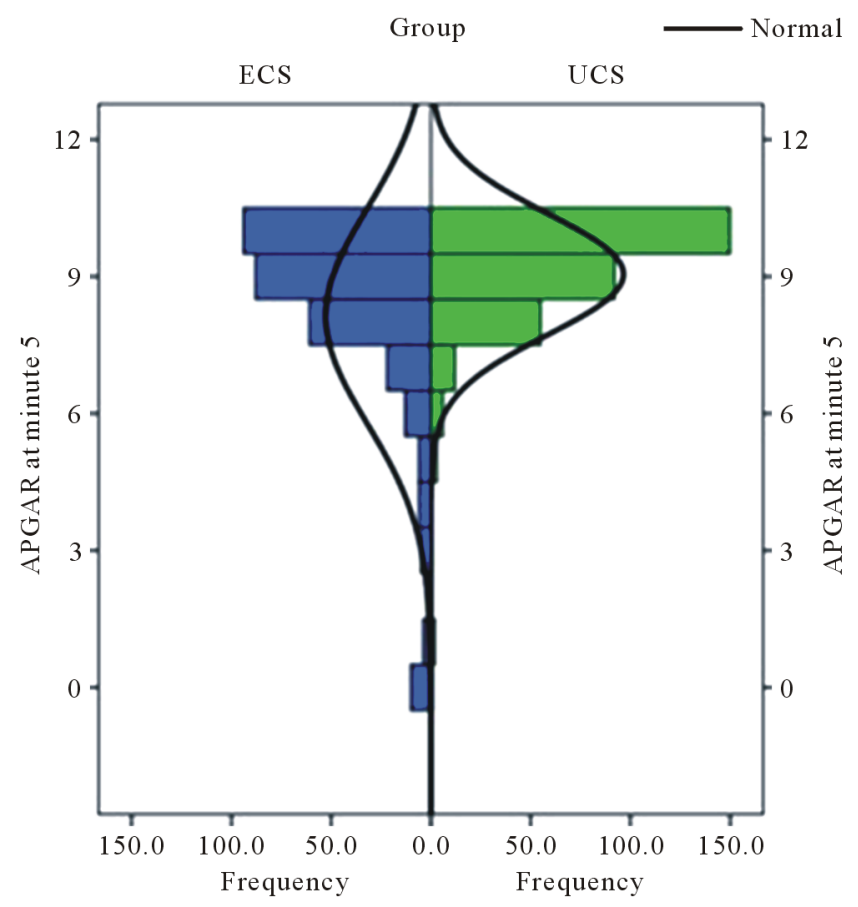

Figure 1. Distribution of APGAR value after 5 minutes for cases and controls. The figure shows the five minute APGAR levels of neonates which underwent emergency cesarean section and urgent cesarean section. The difference between the two groups was significant in the Wilcoxon test with $\mathrm{p}<0.001$. 


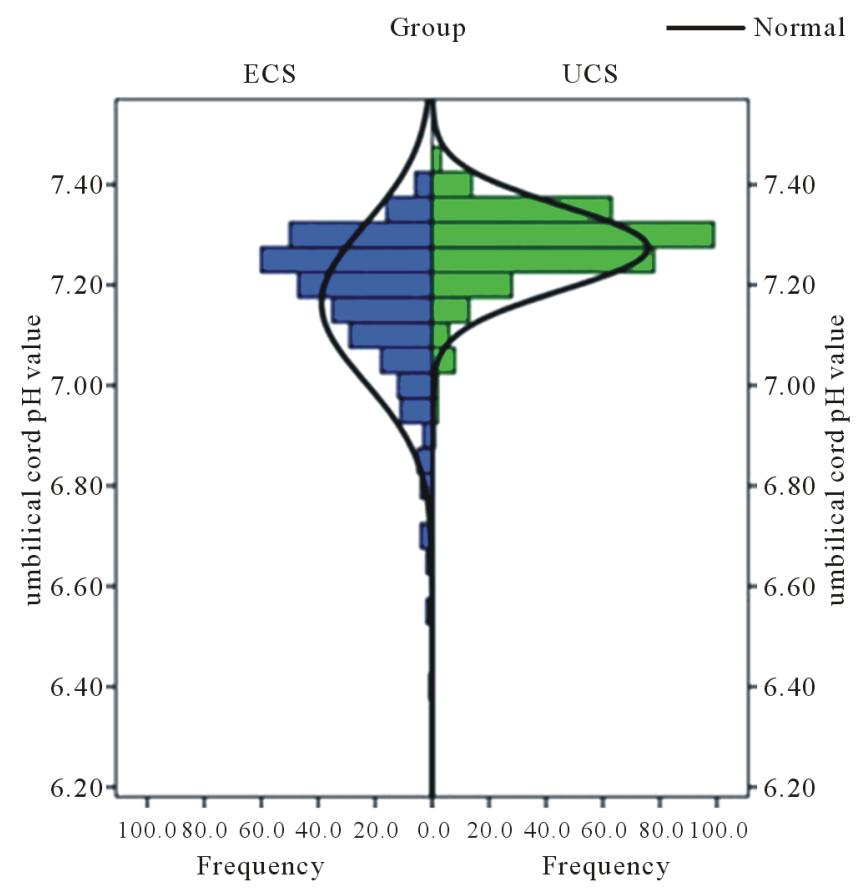

Figure 2. Distribution of umbilical cord $\mathrm{pH}$ value for cases and controls. The figure shows the umbilical cord $\mathrm{pH}$ values of neonates born by emergency cesarean section compared with neonates which underwent urgent cesarean section. The difference between the two groups was significant in the Wilcoxon test with $\mathrm{p}<0.001$.

neonatal outcome are partially explainable regarding the underlying pathologies. Indications for ECS are acute life threatening events, whereas UCS are conducted for maternal or fetal compromise which is not immediately life threatening.

Studies have shown that a shorter DDI is associated with poorer fetal outcomes [8]-[10], tough the hypoxic event is finished earlier. Theories to explain this phenomenon include, that the anxiety for the woman generated by the decision for ECS may provoke increased maternal catecholamine release that initially causes reduced perfusion of the placental bed and gas exchange, causing temporal fetal acidosis [8]. Even though the uterine vessels should be constricted due to catecholamine release, the blood loss of women undergoing ECS was higher than in women undergoing UCS. The vasoconstriction of blood vessels in the uterus is induced by norepinephrine, whereas epinephrine causes vasodilatation. Segal et al. showed that the beginning of efficient analgesia reduces the level of epinephrine [11]. The analgesia at ECS is probably not as efficient as at UCS because of the fast induction of anesthesia. However not every circumstance having influence to the blood loss is known.

Women undergoing ECS were in the $36^{\text {th }}$ week of gestation, whereas women with UCS were in the $38^{\text {th }}$ week. This fact surely affects the outcome, especially the neonatal outcome. The mortality of "late preterm" is higher compared with mature new-born [12]. Even though in this study the neonates were matched by gestational week to diminish this influence of gestational age at the mortality, the perinatal mortality was higher for ECS than UCS (8.3\% vs. 1.7\%). The perinatal mortality was also influenced by the fact, if the pregnancy was singleton or multiple. Singletons had a perinatal mortality of 3.8\%, twins of 8.1\%. Singletons born with ECS had a higher mortality than singletons born with UCS (5.7\% vs. 1.4\%). Twins born with ECS had a higher mortality than twins born with UCS (17.41\% vs. 2.63\%). Admission to NICU was more frequent for twins; in the case group the probability was higher than in the control group. (ECS vs. UCS singletons $54.26 \%$ vs. $35.22 \%$, twins $77.7 \%$ vs. 63.72\%). Other studies showed that the perinatal mortality is higher for twins than for singletons and that twins were more often transferred to NICU [13] [14]. The Apgar score after one, five and ten minutes was different in the case and the control groups. The Apgar score was initially conceived as predictor for survival and to evaluate resuscitation, but not to predict the long term outcome. The score is not only influenced by gesta- 
tional age, maternal medication and resuscitation but also by neurological and respiratory complications. The five-minute Apgar score is not a good marker for an acute hypoxic event during birth [15] [16]. In addition the condition leading to the conduction of an ECS may have influence on the Apgar levels. In our study singletons had a higher five and ten minute Apgar score than twins. Although the Apgar levels were significantly lower in the case group, the validity is questionable because most of the children in the case and the control groups achieved high levels from 7 - 10, which are classified as normal [15].

The $\mathrm{pH}$ values were lower in the case group (median 7.20) than in the control group (median 7.29). Eskes et al. had shown that at fetal bradycardia, which is often associated with hypoxia, the $\mathrm{pH}$ value declines every minute about 0.006 units [17]. This may also have influence on the lower $\mathrm{pH}$ in the case group. Interestingly the umbilical cord $\mathrm{pH}$ value was lower for singletons than for twins, especially in the case group. Georgieva et al. had shown that the umbilical cord $\mathrm{pH}$ is a good predictor for low Apgar score, need for resuscitation, ventilation with mask, seizures and other cerebral problems including death [18].

Various studies had shown that the second born twin has a poorer outcome than the first born [19] [20]. This could not be repeated in this study.

\section{Conclusions}

In summary, the maternal and fetal outcome is poorer in ECS than UCS. The maternal blood loss is higher, hemorrhage is more frequent, just as puerperal anemia. Apgar levels and umbilical cord $\mathrm{pH}$ values are lower at neonates born by ECS. Twins had lower Apgar levels, but higher umbilical cord $\mathrm{pH}$ values. The perinatal mortality is higher for singletons than for twins.

The study has some limitations, in parts caused by the retrospective design with possible errors in data selection. The number of investigated patients was low, especially for twin pregnancies, which could also reduce the validity of the study.

\section{Condensation}

Comparison of the maternal and neonatal outcome for singletons and twins between emergency and urgent cesarean sections.

\section{Conflict of Interest}

The authors report no conflict of interest.

\section{References}

[1] Lucas, D.N., Yentis, S.M., Kinsella, S.M., Holdcroft, A., May, A.E., Wee, M., et al. (2000) Urgency of Caesarean Section: A New Classification. Journal of the Royal Society of Medicine, 93, 346-350.

[2] Lurie, S., Sulema, V. and Kohen-Sacher, B. (2004) The Decision to Delivery Interval in Emergency and Non-Urgent Cesarean Sections. European Journal of Obstetrics \& Gynecology and Reproductive Biology, 113, 182-185. http://dx.doi.org/10.1016/j.ejogrb.2003.09.022

[3] Helmy, W.H., Jolaoso, A.S., Ifaturoti, O.O., Afify, S.A. and Jones, M.H. (2002) The Decision-to-Delivery Interval for Emergency Caesarean Section: Is 30 Minutes a Realistic Target? BJOG: An International Journal of Obstetrics \& Gynaecology, 109, 505-508. http://dx.doi.org/10.1111/j.1471-0528.2002.00491.x

[4] Hillemanns, P.H.H., Rebhan, H. and Knitza, R. (1996) Notsectio-Organisation und E-E-Zeit. Geburtshilfe und Frauenheilkunde, 56, 423-430. http://dx.doi.org/10.1055/s-2007-1023258

[5] DGGG (2010) Stellungnahme zur Frage der erlaubten Zeit zwischen Indikationsstellung und Sectio (E-E-Zeit) bei einer Notlage. Leitlinien, Empfehlungen, Stellungnahmen.

[6] ACOG (2009) ACOG Committee Opinion No. 433: Optimal Goals for Anesthesia Care in Obstetrics. Obstetrics \& Gynecology, 113, 1197-1199. http://dx.doi.org/10.1097/AOG.0b013e3181a6d04f

[7] Royal College of Obstetricians and Gynaecologists, Royal College of Anaesthetists, Royal College of Midwives, Royal College of Paediatrics and Child Health (2008) Standards for Maternity Care: Report of a Working Party. RCOG Press, London. https://www.rcm.org.uk/sites/default/files/WPRMaternityStandards2008.pdf

[8] MacKenzie, I.Z. and Cooke, I. (2001) Prospective 12 Month Study of 30 Minute Decision to Delivery Intervals for “Emergency” Caesarean Section. British Medical Journal, 322, 1334-1335. 
http://dx.doi.org/10.1136/bmj.322.7298.1334

[9] MacKenzie, I.Z. and Cooke, I. (2002) What Is a Reasonable Time from Decision-to-Delivery by Caesarean Section? Evidence from 415 Deliveries. BJOG: An International Journal of Obstetrics \& Gynaecology, 109, 498-504. http://dx.doi.org/10.1111/j.1471-0528.2002.01323.x

[10] Thomas, J., Paranjothy, S. and James, D. (2004) National cross Sectional Survey to Determine whether the Decision to Delivery Interval Is Critical in Emergency Caesarean Section. British Medical Journal, 328, 665. http://dx.doi.org/10.1136/bmj.38031.775845.7C

[11] Segal, S. and Wang, S.Y. (2008) The Effect of Maternal Catecholamines on the Caliber of Gravid Uterine Microvessels. Anesthesia \& Analgesia, 106, 888-892. http://dx.doi.org/10.1213/ane.0b013e3181617451

[12] Tomashek, K.M., Shapiro-Mendoza, C.K., Davidoff, M.J. and Petrini, J.R. (2007) Differences in Mortality between Late-Preterm and Term Singleton Infants in the United States, 1995-2002. The Journal of Pediatrics, 151, 450-456.

[13] Mazhar, S.B., Peerzada, A. and Mahmud, G. (2002) Maternal and Perinatal Complications in Multiple versus Singleton Pregnancies: A Prospective Two Years Study. Journal of Pakistan Medical Association, 52, 143-147.

[14] Pinborg, A., Loft, A. and Andersen, A.N. (2004) Neonatal Outcome in a Danish National Cohort of 8602 Children Born after in Vitro Fertilization or Intracytoplasmic Sperm Injection: The Role of Twin Pregnancy. Acta Obstetricia et Gynecologica Scandinavica, 83, 1071-1078. http://dx.doi.org/10.1111/j.0001-6349.2004.00476.x

[15] ACOG (2006) ACOG Committee Opinion, No. 333: The Apgar Score. Obstetrics \& Gynecology, 107, 1209-1212.

[16] Ehrenstein, V. (2009) Association of Apgar Scores with Death and Neurologic Disability. Journal of Clinical Epidemiology, 1, 45-53. http://dx.doi.org/10.2147/CLEP.S4782

[17] Eskes, T.K. (1993) Uterine Contractions and Their Possible Influence on Fetal Oxygenation. Gynakologe, 26, 39-45.

[18] Georgieva, A., Moulden, M. and Redman, C.W. (2013) Umbilical Cord Gases in Relation to the Neonatal Condition: The EveREst Plot. European Journal of Obstetrics \& Gynecology and Reproductive Biology, 168, 155-160.

[19] Prins, R.P. (1994) The Second-Born Twin: Can We Improve Outcomes? American Journal of Obstetrics and Gynecology, 170, 1649-1657. http://dx.doi.org/10.1016/S0002-9378(94)70336-1

[20] Stein, W., Misselwitz, B. and Schmidt, S. (2008) Twin-to-Twin Delivery Time Interval: Influencing Factors and Effect on Short-Term Outcome of the Second Twin. Acta Obstetricia et Gynecologica Scandinavica, 87, 346-353. http://dx.doi.org/10.1080/00016340801934276 
Scientific Research Publishing (SCIRP) is one of the largest Open Access journal publishers. It is currently publishing more than 200 open access, online, peer-reviewed journals covering a wide range of academic disciplines. SCIRP serves the worldwide academic communities and contributes to the progress and application of science with its publication.

Other selected journals from SCIRP are listed as below. Submit your manuscript to us via either submit@scirp.org or Online Submission Portal.
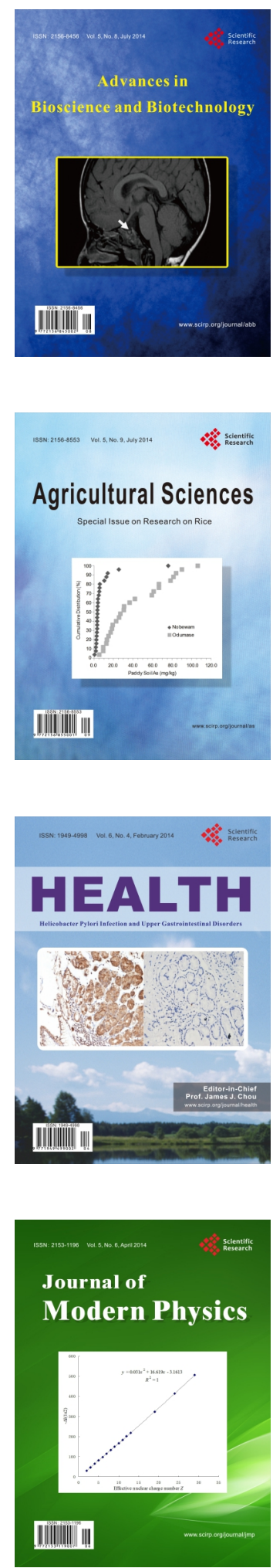
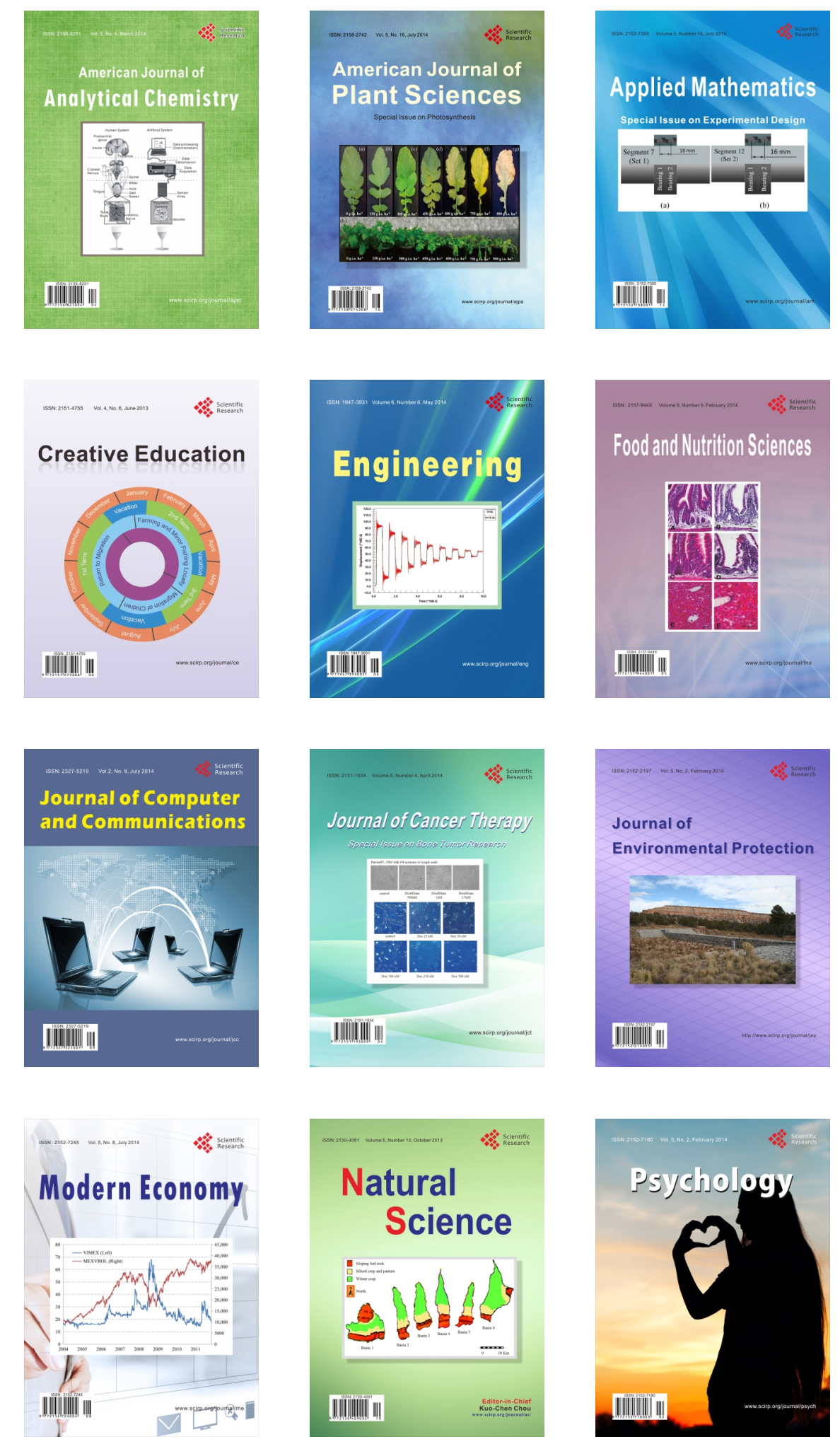